\title{
The Reform of Teaching Mode in Colleges and Universities under the Background of "Internet + Education"
}

\author{
Lijuan Qin ${ }^{1,2, a}$ and Mengqing Fang ${ }^{1,2, b}$ \\ ${ }^{1}$ School of Information Engineering, Zhengzhou University of Industrial Technology, \\ Zhengzhou Henan 451150,PR China \\ ${ }^{2}$ Machine learning and Data researching Institute, Zhengzhou University of Industrial Technology, \\ Zhengzhou Henan 451150,PR China \\ a654259624@qq.com b 903901419@qq.com
}

Keywords: "Internet + Education"; Colleges and Universities; Teaching reform.

\begin{abstract}
Internet + education" is the product of the development of productive forces and technology. It is the concrete application of Internet technology in the field of education and the inevitable trend of teaching reform in colleges and universities. "Internet + education" has rich connotation, it is to adhere to the open concept of the new model of education, is a teacher and student requirements higher teaching model, is conducive to promoting the realization of wisdom education goals and education democratization process. Internet era of large data, "Internet + education" is also known as "wisdom education", which for educational reform, education for the sharing and fairness provides favorable conditions. Under the "Internet + education", colleges and universities how to reform the teaching model, to create a competitive "data strong school" in order to better play the advantages of colleges and universities, social services. This article explores the reform under the Internet big data age from the university teaching mode.
\end{abstract}

\section{Introduction}

In the information age, with the rapid expansion of the digital culture of digital life, people rely on the digital way to obtain knowledge of the degree of continuous improvement, people can easily get a variety of knowledge from the Internet, the Internet era in people's knowledge access channels and ways At the same time, learning methods also change. Prior to the information age, education, such behavior is limited to schools, classrooms, books, etc., but in the information age, people access to learning rights have been expanded, learning not only occurred in the above places, people can phone, television, computer and other information tools, Through APP and other information channels to obtain data. In the Internet age, some knowledge has no need to remember, people can easily get from the Internet billions of dollars of various fine, diversified massive data resources, "Internet $+"$ stage, learning costs greatly reduced, learning this Behavior takes place in an infinite place. Therefore, in the "Internet + " mode, to promote the construction of information technology in colleges and universities, to create "smart campus." With the support of large data and mobile Internet, the reform teaching mode transforms the traditional face-to-face learning into the deep integration of informationization and teaching, research, management and service, and transforms education from teacher-oriented to teacher, Learner-led.

In the "Internet + education" mode, learners learn to change the way, learning this process can be more free and personality to happen. This greatly facilitates the students at the same time, but also changed the relevant educational industry services, the entire education industry units have great significance. Because "Internet + education" to achieve the sharing of educational resources and education fair, in the "Internet + education" background, how to keep up with the pace of the times, promote the "wisdom of the campus" construction, enhance the strength of colleges and universities, strengthen the top design, The sustainable development of colleges and universities, reforming the teaching mode of colleges and universities has become a very realistic subject. With the development of the times, the sustainable development of colleges and universities can not be separated from the reform of educational mode. Colleges and universities need to build "wisdom 
campus", improve the level of running a school to help students more effectively acquire knowledge and promote the fairness and sharing of educational information resources. Here we from the following aspects to explore the "Internet + education" background, the reform of teaching methods in colleges and universities.

\section{Split The Knowledge Points, Reform Teaching Time, Micro-Class Teaching, Improve Student Learning Efficiency}

The traditional teaching class, teaching time is about 45 minutes, but for students, this 45 minutes is not effective learning, especially in the "Internet + " era, students are network information "surrounded by", students can anytime, anywhere In the "Internet + education" era, we can use multimedia and other information technology to miniature knowledge points, Shorten the class, micro-class teaching, so that not only can improve the efficiency of students, but also can guide students according to their own learning situation and progress of personalized self-study and repeat learning. According to the actual teaching experience, students generally focus on the general focus is about 30 minutes, for this situation, we can through the "Internet + " better curriculum design, improve teacher-student interaction, participation. "Internet + education" not only to microblogging, WeChat, client and other social networks, online resources and teachers to integrate, but also to improve the scientific design of curriculum, to achieve knowledge interaction, enhance learning fun, so that students are more interested Learning, curriculum design can add video chat rooms, online games, online forums and other interactive activities of teachers and students, give full play to the advantages of Internet technology, innovative teaching model.

\section{Online education, educational equity and resource sharing}

If the education industry is divided into large classes, small classes, 1 to 1 education, online education four models, the traditional education model, the first three blocks of development has been more mature, and the fourth largest module, "online education" is still in Growth stage, as a new thing in the field of education, "Internet + education" conform to the wave of information technology development, its emergence, to solve the educational resource information asymmetry problem is an important direction for the future development of the education industry. Online education is through online video teaching, teachers and students will be connected to create a cross-time, cross-space communication platform, the Internet as a bridge between teachers and students, through learning can find suitable for their educational resources. Based on this model, compared to the traditional education model, the Internet has changed the information asymmetry, the field of education online and offline can be complementary, this application can also be used in the school management and student services.

Since 2012, an online course called MOOCs has swept the world's major colleges and universities, distinguishing from traditional teaching models, and this large-scale open-ended web-based curriculum has no human and geospatial constraints, with the Internet Development, the popularity of smart phones, any person as long as access to the Internet, will be able to accept higher education. Mu class to break the traditional classroom teaching mode, the learner can register anytime, anywhere to enjoy the teacher's classroom teaching, students can choose according to their own interest in the MOOCs study, learners can choose the curriculum. In addition, Mu class can be achieved through the network technology curriculum theory and fun of the unity, in the Mu class learning, the course focused on a particular problem, in which case, $\mathrm{Mu}$ class can be divided into dozens of minutes, this time Cutting a great deal to avoid a high degree of concentration of learners brain fatigue affect the efficiency of this network there is an advantage that is in the course can add many interesting links to achieve online and offline interaction, such as teachers ask questions, students Only to answer correctly to continue the following courses to learn, an increase of teacher-student interaction. MOOCs also brought about changes in the relationship between the traditional teachers and students, Internet technology has changed the state between the traditional teachers self-proclaimed, teachers through the network to achieve more exchanges, the traditional 
classroom teachers and students are limited by the classroom, Class that better reflects the fair interaction between teachers and students on the benign interaction. Online teaching has changed the traditional teaching philosophy, in the "Internet +" background, the requirements of the teaching philosophy of colleges and universities have to change.

\section{Optimize the Basic Network Environment, Build a Digital Campus Platform.}

Digital education and teaching have the advantages of space-time freedom, resource sharing, system opening, easy cooperation and so on. The foundation of the construction of digital campus is the construction of campus network, the system hardware clearance is the prerequisite for the construction of digital teaching platform system, the construction and development of campus network, so that the campus digital platform system management and application level. Network management environment optimization, safe and efficient hardware protection system construction, information and data platform construction, through the construction of data sharing platform, unified data specifications and standards for teaching, research, management and other data resources integration, in order to achieve teachers and students online Interaction, reform teaching methods laid the foundation. Colleges and universities should actively promote the comprehensive use of information technology in education and teaching, you can learn from the advanced experience of foreign development MOOCs, build and optimize their own online teaching platform, pilot online and offline mixed teaching mode, the implementation of personalized teaching, Interaction with people, people and knowledge, people and teaching environment. Positive thinking, bold exploration, careful selection, organization of network courses, innovative teaching methods and methods, the introduction of colleges and universities with their own characteristics of professional courses to expand the influence of university brand.

\section{Construction of Information Technology Team to Enhance the Level of Information Technology Teachers}

"Online education" is a teacher and team learning team coordination with a learning model, it emphasizes teaching designers, lecturers, Internet technical staff work together. Good "online education" course is inseparable from the serious design, well prepared, which often requires the relevant personnel to invest a lot of time and effort. Therefore, colleges and universities should actively promote the construction of information technology team, training information team members, including information systems management personnel, master the "Internet +" environment management, to quickly and accurately respond to the challenges of information technology. Through the study of "Internet + , environment management model, they can actively participate in the construction of university network courses. There are more teachers to master the" Internet + "environment under the new teaching methods and methods, with the" Internet + education " Environment, education, data processing, data mining, data maintenance and other professional information technology, the development of information technology, including the basic hardware maintenance, network maintenance, software development, data processing, data mining, data maintenance and other professional information technology, Through the strengthening of information technology team building, to create incentives to encourage teachers to train the training mechanism to support the construction of teacher information team to protect multi-level uninterrupted talent training program to promote the division of teachers and integrated management of specialized.

The openness of the Internet makes the dissemination of knowledge break through the limitations of time, which leads to the substantive and structural changes of the elements such as educational objects and educational content. The traditional model of colleges and universities can not meet this change, which leads to the reform of educational mode. With the advent of information technology, mixed teaching, micro-class, Mu class, etc., is a typical way of using the Internet platform, practice teaching process, "Internet + education" fundamentally changed the traditional teaching of the role of teachers and students, teachers And then the only source of 
knowledge acquired by learners, the openness of the Internet makes learners not only learners but also contributors to knowledge. "Internet + education" can not completely replace the traditional teaching mode of colleges and universities, but colleges and universities should actively explore the "Internet + " under the background of the education of colleges and universities, although the "Internet + education" can not completely replace the traditional teaching mode of colleges and universities, Development direction, and promote the informationization of college education.

\section{References}

[1] Guihua Liu. On the Innovation of Teaching Mode in Colleges and Universities under the Background of "Internet + " [J]. Journal of Higher Education, 2017.

[2] Bin Chen. "Internet + education" is the inevitable trend of university teaching reform[J] .Chongqing Higher Education Research, 2017.

[3] Xiangling Zou. Research on the Teaching Mode of Inverted Course under the Background of "Internet+" [J]. Journal of Henan Radio \& TV University, 2016,04: 82-85.

[4] Yongli Qin. "Internet +" under the background of the design of small courses and flip the course application [J]. Chinese Journal of Education, 2016, 11: 116.

[5] Xiuping Wang, Linglin Wang. On the Innovation of Experimental Teaching Mode in Colleges and Universities under the Background of "Internet+"[J].Education Teaching Forum,2017.

[6] Li Lu. Discussion on Teaching Reform of "University Computer Basis" in Colleges and Universities under the Background of "Internet + Education"[J]. Computer Knowledge and Technology, 2016.

[7] Guiru Liu. Reflections on the Reform of Colleges and Universities in Colleges and Universities Based on "Internet+"[J]. Computer Knowledge and Technology, 2016(8). 